\title{
Influence of the Feed Powder Composition in Mechanical Properties of AlN-Nano-Reinforced Aluminium Composites Coatings Deposited by Reactive Direct Laser Deposition
}

\author{
Ainhoa Riquelme ${ }^{1, *}$, Pilar Rodrigo ${ }^{1}$, María Dolores Escalera-Rodriguez ${ }^{1}$, \\ Pablo García-Fogeda ${ }^{2}$ and Joaquín Rams ${ }^{1}$ \\ 1 Materials Science and Engineering Group, Escuela Superior de Ciencias Experimentales \\ y Tecnología (ESCET), Universidad Rey Juan Carlos, 28933 Móstoles (Madrid), Spain; \\ pilar.rodrigo@urjc.es (P.R.); dolores.escalera@urjc.es (M.D.E.-R.); joaquin.rams@urjc.es (J.R.) \\ 2 ETS de la Ingeniería Aeronáutica y del Espacio, Universidad Politécnica de Madrid, 28040 Madrid, Spain; \\ pablo.garciafogeda@upm.es \\ * Correspondence: ainhoa.riquelme.aguado@urjc.es; Tel.: +34914884688
}

Received: 18 June 2020; Accepted: 6 July 2020; Published: 10 July 2020

\begin{abstract}
Aluminium matrix composite coatings reinforced with AlN nanopaticles have been manufactured by direct laser deposition on an AA6082 alloy substrate. The reinforcement of the composite has been generated by the direct nitridation reaction of the feed powder with the carrier gas $\left(\mathrm{N}_{2}\right)$ heated by an HPDL beam during the fabrication of the coating. The coating obtained consists of nano-sized AlN particles in an aluminium matrix, and the crystalline structure of the obtained AlN depends on the characteristics of the powder used. In this work, the influence of the feed powder composition is studied by comparison among pure aluminium, Al12-Si alloy, and AA6061 alloy, on the formation of AlN and its crystalline structure. A correlation was established between the temperature distribution reached by the particles, their composition, and the nitridation reaction mechanisms. The effect of the reinforcement was evaluated by comparing the microstructure and mechanical properties (microhardness, nanoindentation) of the composite costing with non-reinforced $\mathrm{Al}$ coatings and uncoated AA6082. Al/AlN composite coatings with improved properties were achieved, reaching hardness values that were $65 \%$ higher than coatings without reinforcement.
\end{abstract}

Keywords: nitridation reaction; aluminium matrix composites; direct laser deposition; transmission electron microscopy; microstructure; nanoindentation

\section{Introduction}

Improving the efficiency of the means of transport in order to reduce fuel consumption and pollution is currently one of the main challenges that the transport industries are facing. For this reason, there is an increasing interest in research focussed on the fabrication of light-weight structural materials with improved properties. Aluminium alloys have a high processing capacity and a reasonable cost together with a reduced density, which gives them high specific values of strength and elastic modulus. For this reason, they have received great attention for applications in many sectors, especially in transport. 6XXX series alloys are widely used in the automotive industry, and specifically, 6082 is used for sections that require high tensile strengths. Mrówka-Nowotnik et al. [1] identified all the intermetallic phases formed in 6082 alumnium alloy casting, and Birol [2] investigated the effect of ageing treatments T5 and T6 on the final properties of AA6082 alloy; they found that the quench is the most critical processing parameter. 
However, in the transport sector, some components work under wear conditions and/or are subjected to mechanical loads, so it is necessary to use materials with improved properties. Aluminium matrix composites (AMC) are very promising materials due to their lightness, strength, and wear resistance. Most of the methods used to fabricate bulk aluminium composites employ the liquid route, in which the ceramic reinforcement is added to a molten aluminium alloy. The main problems with these methods are the inhomogeneous reinforcement distribution and the reinforcement/matrix interface reactions that can produce harmful intermetallic phases and consume the reinforcement. $\mathrm{Al}-\mathrm{SiC}$ metal matrix composites are the most studied system. Other authors investigated the interfacial reactions in $\mathrm{Al} / \mathrm{SiCw}$ composites made by liquid metal infiltration, and they found that the consumption of $\mathrm{SiC}$ is inversely proportional to $\mathrm{SiC}$ volume fraction, and the $\mathrm{Al}-\mathrm{SiC}$ reaction exits from $670{ }^{\circ} \mathrm{C}$. Therefore, depending on the matrix-reinforcement system, it may be necessary to find a way to minimise the interfacial reactions [3]. Ureña et al. [4] studied the application of oxidation treatments to $\mathrm{SiC}$ particles to minimise the interfacial reactions of these systems and reduce the formation of $\mathrm{Al}_{4} \mathrm{C}_{3}$ crystals.

The search for improving the surface properties has promoted a growing interest in research focussed on the use of aluminium composite coatings on aluminium substrates and other light alloys to increase the surface properties without increasing the weight of the bulk material. Kumar et al. [5] reported about cold-sprayed coatings with different powder compositions of $\mathrm{SiC}$ on aluminium substrates, and they found that the wear performance of the coating enhances when the $\mathrm{SiC}$ particulate volume increased with the heat treatments. Rodrigo et al. [6] investigated the wear behaviour of $\mathrm{Al} / \mathrm{SiCp}$ composites coatings prepared by oxy-acetylene flame thermal spraying on ZE41 magnesium alloy, obtaining that the wear rate of as-spayed coatings with 12.3 vol. $\%$ SiCp was $40 \%$ lower than that of the substrate. Riquelme et al. [7] deposited Al/SiCp coatings by a laser cladding process, and they observed that the particulates reacted with the aluminium and formed $\mathrm{Al}_{4} \mathrm{C}_{3}$. To minimise this problem, they modified the composition of the feeding powder by adding $\mathrm{Si}$ and Ti.

The use of AlN as a reinforcement for aluminium matrices is not widespread, but its properties make it a good candidate for this. It has high thermal conductivity, high mechanical resistance, low electrical conductivity, low density, and a low coefficient of thermal expansion; all this is combined with a high resistance to degradation in molten Al. A359/AlN composites have been manufactured with appropriate mechanical and functional properties for automotive applications by means of stir and squeeze casting [8]. However, AlN powder is expensive and has high fabrication costs. Borgonovo et al. [9] reported that generating in situ AlN in the aluminium matrix reduces manufacturing costs and guarantees a perfect integration of the reinforcement in the matrix composite.

In situ AlN/aluminium composites have been fabricated by direct reaction between molten aluminium and nitrogen or $\mathrm{NH}_{3}$ in direct melt nitridation (the PRIMEX method) [10]. Hou et al. [11] and Hall et al. [12] found that aluminium nitridation is a thermodynamically exothermic process and energetically favourable for an extensive range of temperatures. The nitridation reaction from nitrogen is:

$$
2 \mathrm{Al}+\mathrm{N}_{2} \rightarrow 2 \mathrm{AlN}
$$

In addition, it is possible to use $\mathrm{NH}_{3}$ as a nitrogen source:

$$
2 \mathrm{Al}+2 \mathrm{NH}_{3} \rightarrow 2 \mathrm{AlN}+3 \mathrm{H}_{2}
$$

Borgonovo and Apelian (2011) [13] reported that the standard manufacturing techniques, apart from having high fabrication costs, produce materials that have pores because of the degradation caused by reactions between the matrix and the reinforcement.

Direct Laser Deposition (DLD) is a very effective way to obtain coatings on metal structures. The use of a laser as a power source offers some advantages in comparison with other fabrication methods. For instance, non-restricted geometries can be fabricated by laser technologies. Zhong and Liu [14] collected in a review article the influence of the rapid heating/cooling, which is a characteristic of laser 
cladding, in the final microstructure of the material deposited. One of the advantages is that the DLD coating process can be used to fabricate better coatings with minimal thermal distortion and dilution and improved surface quality. Song et al. [15] fabricated Ti6Al4V coatings on pure titanium with enhanced wear behaviour thanks to the ultrafine microstructure, high hardness, and high residual stress of the coatings.

Currently, DLD is only used to fabricate parts or coatings that have the same composition of the powders used. Depositing a composite coating, particularly with a nano-sized reinforcement, would strongly improve the properties of the coated pieces, but the compositions of the commercial powders for DLD are very limited, and no aluminium composites are available. To solve this situation, in this work, we propose a novel process based on the formation of an aluminium alloy composite reinforced with AIN particles by the in situ reaction between an aluminium alloy and nitrogen under the irradiation of the laser used during DLD, so that the composite is formed while the composite is being deposited. This is an innovative process that can be afterwards applied on other additive manufacturing processes, and this study shows that the surface properties obtained largely exceed those of the alloys conventionally used in the automotive and aerospace industries. Moreover, the cost is equivalent to that of coating with any other DLD process.

Riquelme et al. [16] in a previous work have studied the effect of the processing parameters on the additive manufacturing of wall-shaped pieces, using Al-12Si as a feed powder. In these pieces, the formation of AlN nanoparticles has been detected. In the present work, the influence of the composition feed powder on the generated AlN crystalline structure has been investigated. In addition, the relationship between the crystalline structure and the mechanical properties of the manufactured coatings has been evaluated. Al/AIN nano-reinforced composite coatings on AA6082 alloy have been fabricated by Direct Laser Deposition in an $\mathrm{N}_{2}$ atmosphere. The laser heats the particles, inducing a nitridation reaction. Nitrided powders were analysed by scanning and transmission electron microscopy (SEM and TEM). The effect of using different aluminium alloys has been evaluated, and the temperature of the particles in the laser beam has been modelled. The correlation between the temperature of the particles and the crystalline structure of AlN formed has been found. The coatings were analysed by SEM, and the micromechanical properties were evaluated using nanoindentation tests and Vickers microhardness. The coatings that had AlN particles showed increases in hardness of up to $65 \%$ compared to the unreinforced material. Nanoindentation maps have identified the hardening effect of the particles in the matrix.

\section{Materials and Methods}

Different aluminium alloy powders were tested to evaluate the effect of the composition of the alloy used: pure Al, Al-12Si, and AA6061. Table 1 contains the average size and composition of the alloys.

Table 1. Composition and size of the alloy powders used.

\begin{tabular}{|c|c|c|c|c|}
\hline Product & Manufacturer & $\mathrm{D} 50(\mu \mathrm{m})$ & Composition (wt.\%) & Composite Name Used \\
\hline $\mathrm{Al}$ & Oerlikon Metco & 70 & $99.74 \mathrm{Al}$ & $\mathrm{Al} / \mathrm{AlN}$ \\
\hline $\mathrm{Al}-12 \mathrm{Si}$ & Oerlikon Metco & 60 & $12 \mathrm{Si}, 88 \mathrm{Al}$ & Al-12Si/AlN \\
\hline AA6061 & $\begin{array}{l}\text { Aluminium } \\
\text { Powder } \\
\text { Company }\end{array}$ & 75 & $\begin{array}{c}0.8-1.2 \mathrm{Mg}, 0.4-0.8 \mathrm{Si}, \\
0.15-0.4 \mathrm{Cu}, 0.04-0.35 \mathrm{Cr}, \\
<0.7 \mathrm{Fe},<0.15 \mathrm{Mn},<0.15 \mathrm{Ti}, \\
\text { balance } \mathrm{Al} .\end{array}$ & AA6061/AlN \\
\hline
\end{tabular}

Aluminium matrix composites reinforced with AlN on AA6082 aluminium alloy were manufactured by DLD. The AlN reinforcement was obtained by a direct nitridation reaction between nitrogen gas and aluminium particles during the fabrication process.

The equipment used consists of an HPDL (ROFIN DL013S) with a maximum power of $1300 \mathrm{~W}$ that emits at 808 and 940 nm, equipped with a cladding coaxial nozzle (Fraunhofer IWS COAX 8, 
Dresden, German), and placed on a 6-axis robot from ABB. The processing conditions of the nitrogen gas used were a pressure of $4.5 \mathrm{~atm}$ and flow rates of $0.05 \mathrm{~L} \cdot \mathrm{s}^{-1}$. The laser power used was $1 \mathrm{~kW}$, the powder feeding rate was $3 \mathrm{~g} / \mathrm{min}$, and the laser focus overlapped with the powder focus.

After the laser treatment, the composite powders were examined by SEM Hitachi equipped (Mannheim, Germany) with an energy-dispersive X-ray spectrometer (EDS), TEM, selected area electron diffraction (SAED), and nuclear magnetic resonance (NMR). The particle size distribution was measured by Leica Application Suite image analysis software. SEM images with a high number of particles (> 50 particles) were used to measure their size distribution.

To evaluate the effect of the AlN reinforcement in the composite matrix coating properties, $\mathrm{Al}$ coatings were manufactured by DLD without reinforcement. The process used for the fabrication was the same, applying the same control parameters, but using argon instead of nitrogen.

$\mathrm{Al} / \mathrm{AlN}$ coatings were made on an AA6082 alloy with a T6 treatment in the form of coupons of $30 \times 30 \times 5 \mathrm{~mm}^{3}$. The nominal composition is shown in Table 2. The surface of the substrates was prepared by blasting with brown corundum $\left(D_{50}=60 \mu \mathrm{m}\right)$ for $1 \mathrm{~min}$. The substrate roughness after blasting was $14.5 \mu \mathrm{m}$ (arithmetical mean height, $S_{a}$ ). The manufacturing parameters of the coatings are shown in Table 3.

Table 2. Composition of the coupons used as substrate.

\begin{tabular}{cc}
\hline Alloy & Composition (wt \%) \\
\hline AA6082 & $1.05 \mathrm{Si} ; 0.23 \mathrm{Fe} ; 0.03 \mathrm{Cu} ; 0.57 \mathrm{Mg}, 0.57 \mathrm{Mn} ; 0.02 \mathrm{Zn} ; 0.02 \mathrm{Ti}$, balance Al. \\
\hline
\end{tabular}

Table 3. Direct Laser Deposition control parameters.

\begin{tabular}{cccc}
\hline Laser Power $(\mathbf{W})$ & Scan Speed $(\mathbf{m m} / \mathbf{s})$ & $\begin{array}{c}\text { Distance between Laser } \\
\text { Lines }(\mathbf{m m})\end{array}$ & $\begin{array}{c}\text { Powder Feeding Rate } \\
(\mathrm{g} / \mathbf{m i n})\end{array}$ \\
\hline 1000 & 10 & 0.7 & 3 \\
\hline
\end{tabular}

The samples fabricated were cut by their cross-section and polished. Samples were analysed by SEM and X-ray diffraction (XRD). Reinforcement percentage was calculated by using image analysis software (Leica Application Suite, Buffalo Grove, IL, USA). Vickers microhardness profile was obtained on the cross-section with a Shimadzu microhardness tester (Kyoto, Japan) with $1 \mathrm{gf}$ load for $15 \mathrm{~s}$. The nanohardness of the different phases of the composite coatings was measured using a Berkovich indenter (MTS nanoindenter, Eden Prairie, MN, USA) by applying $0.5 \mathrm{gf}$ for $10 \mathrm{~s} ; 10 \times 10,15 \times 15$, and $20 \times 20$ nanoindentation matrices were done.

\section{Results}

\subsection{Initial Powder Characteristics}

Figure 1 shows images of the powder particles used and their distribution. The as-received $\mathrm{Al}$ powder showed quasi-spherical particles with some satellites (Figure 1a). The size distribution was $+50-100 \mu \mathrm{m}$ and matched the values provided by the manufacturer.

The Al-12Si alloy particles had a spherical shape with few satellites (Figure 1b). The size distribution of the Al-12Si alloy differed from that provided by the manufacturer by $13.4 \%(+40-90 \mu \mathrm{m})$.

The size distribution of the AA6061 powders (Figure 1c) was not homogeneous, and particles with elongated shapes could be observed. The size of the particles was between 10 and $100 \mu \mathrm{m}$, with an average dimension (D50) of $75 \mu \mathrm{m}$. The particles showed a smooth surface, and many were aggregated. 

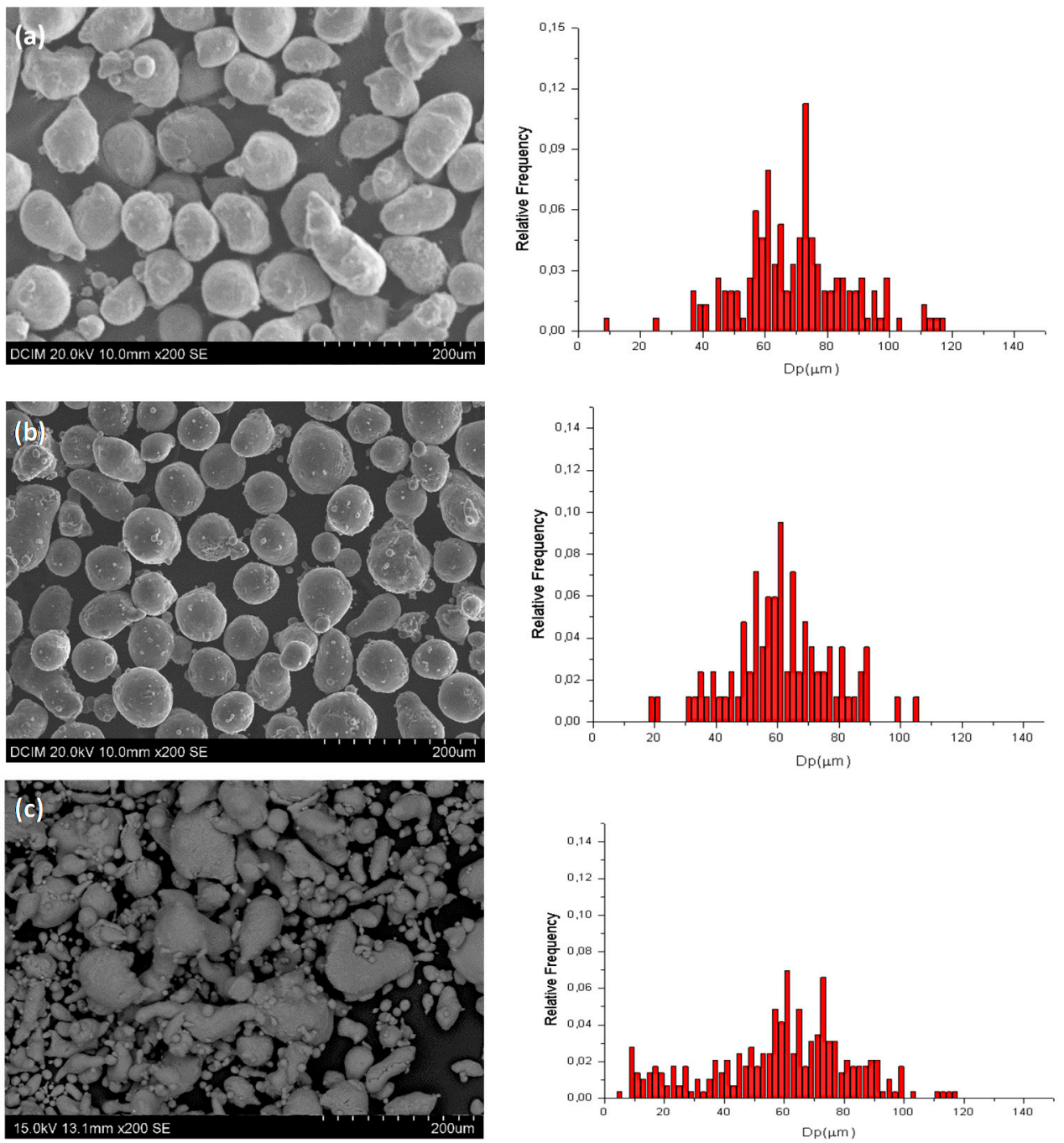

Figure 1. (a) Al particles as-received, (b) Al-12Si particle as-received, (c) AA6061 as-received.

\subsection{Laser Treated Powder Characterisation}

The particles were submitted to a reactive process in the laser beam in a nitrogen flow, and in order to characterise them, were not deposited on a substrate, but were collected in a metallic box.

NMR analysis of laser-treated powders is shown in Figure 2. In all three cases, the peaks corresponding to cubic Al were identified. Apart from this peak, another peak was observed in all the samples at $112 \mathrm{ppm}$; this value corresponds to hexagonal AlN, and it has been assigned by Xiong et al. [17] to the tetrahedrally coordinated $\mathrm{AlN}_{4}$ units.

SEM and TEM images of pure Al powders (Figure 3) showed changes in the morphology of the particles surface after the laser treatment. The powder was slightly deformed due to melting and solidification (Figure 3a), but the general shape of the particles had not changed. Figure $3 \mathrm{~b}$ shows a detail of a laser-treated Al particle in which reaction products were formed at the surface of the aluminium particle. Electron diffraction patterns taken in different zones of this layer showed that there were amorphous zones (Figure 3c) and nanocrystalline zones (Figure 3d). SAED patterns indicate the existence of AlN with different crystalline structures: Figure 3e shows a zone in which the SAED pattern corresponds with an AlN cubic structure (F-43m) oriented on the zone axis [01 $\overline{1}]$, and Figure $3 \mathrm{f}$ shows a SAED pattern that correlates with hexagonal AlN (P-63mc) on the zone axis [010]. 
(a)

(b)

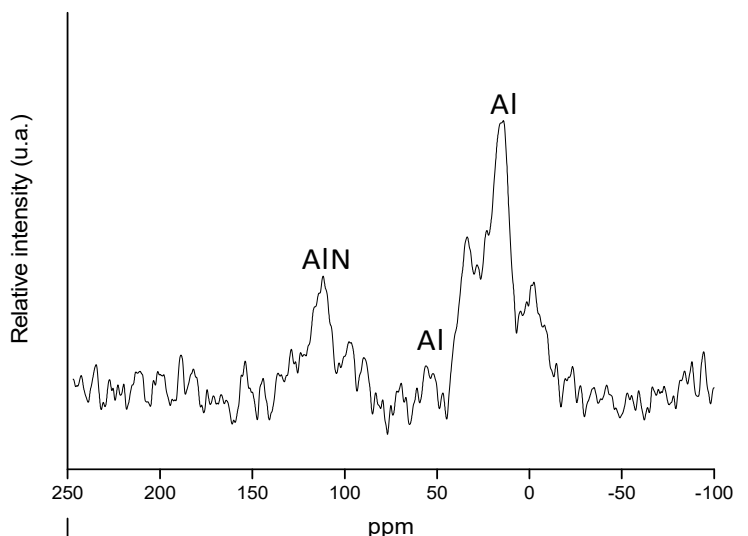

(c)
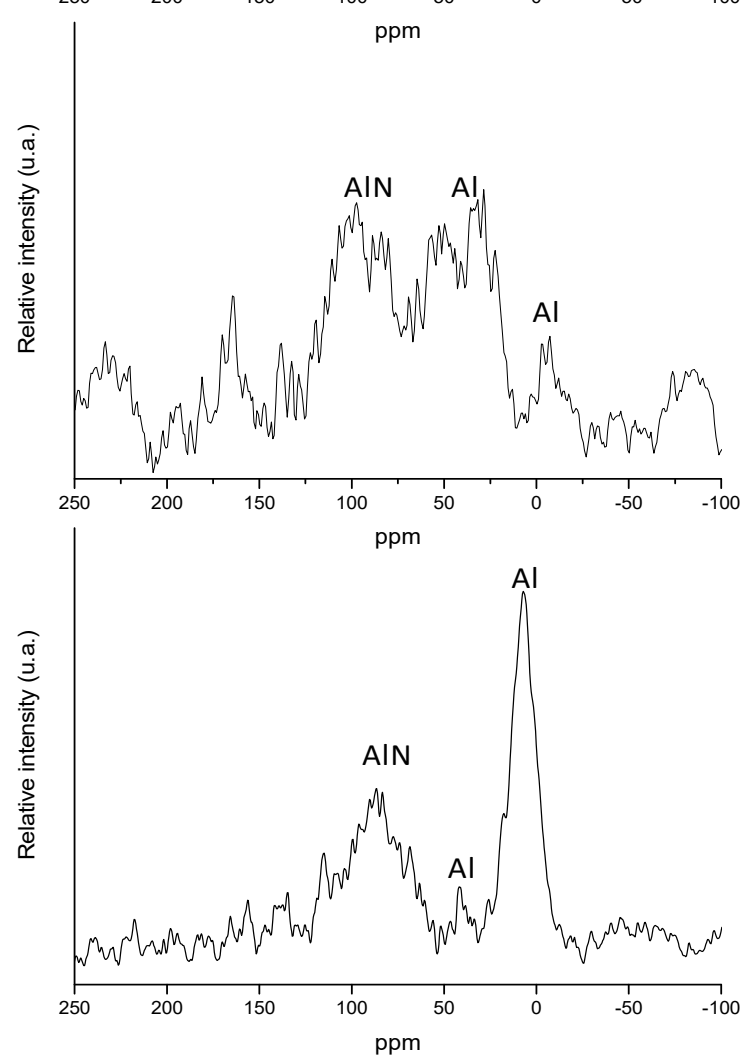

Figure 2. (a) ${ }^{27} \mathrm{Al}$ NMR spectra of $\mathrm{Al}$ pure/AlN particles; (b) DRX pattern and ${ }^{27} \mathrm{Al}$ MAS NMR spectra of Al-12Si/AlN particles; (c) DRX pattern and ${ }^{27} \mathrm{Al}$ MAS NMR spectra of AA6061/AlN particles.

The Al-12Si/AlN laser-treated powder did not change its overall shape, although some deformation and roughness appeared on its surface (Figure $4 \mathrm{a}$ ). Figure $4 \mathrm{~b}$ shows the TEM image of the surface of an Al-12Si/AlN particle in which zones with different characteristics were observed. The diffraction pattern on the particle surface showed the presence of AlN that varied from partially nanocrystalline in Zone A (Figure 4c) to cubic (F43m) in Zone B (Figure 4d; the pattern is correlated with zone axis [0 01 1]).

The shape and roughness of the powder surface of 60661 were strongly modified by the laser treatment. The particles were more elongated and showed a higher surface roughness (Figure 5a). The TEM images showed that small crystals were formed on the surface (Figure 5b). Figure 5c shows one of these crystals and its SAED pattern, which corresponds to a cubic structure for the AlN in

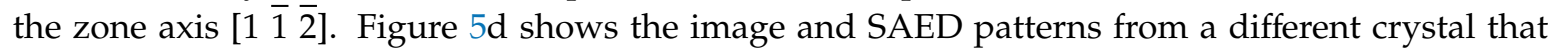
coincides with the hexagonal AlN P-63mc oriented on the zone axis [2 10$]$. 

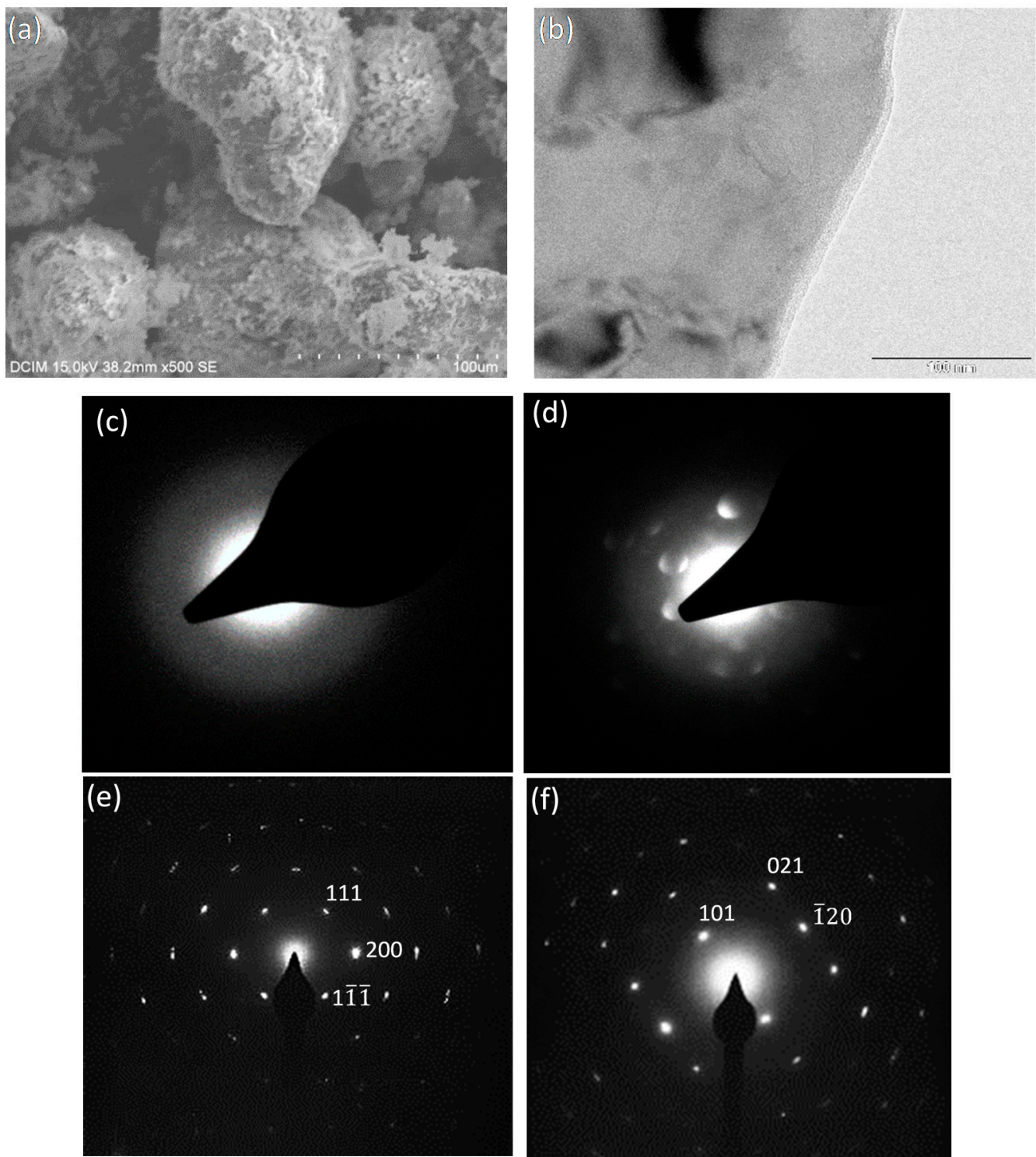

Figure 3. (a) Al/AlN powder (b) TEM bright field (BF) micrograph of (a) Al/AlN interface; (b) Detail of AlN coating; (c) Al/AlN amorphous ED; (d) Al/Al nanocrystal ED; (e) Al/AlN cubic ED; (f) Al/AlN hexagonal ED.

All the powders were modified by the laser-induced nitridation and by the melting and solidification process. The particles surface showed more roughness, and the shape was less spherical. Nevertheless, according to the shape and surface texture, these powders can be used in additive manufacturing with similar viability as the initial powders, although according to the research of Dawes et al. [18], its flowability may be slightly reduced. 

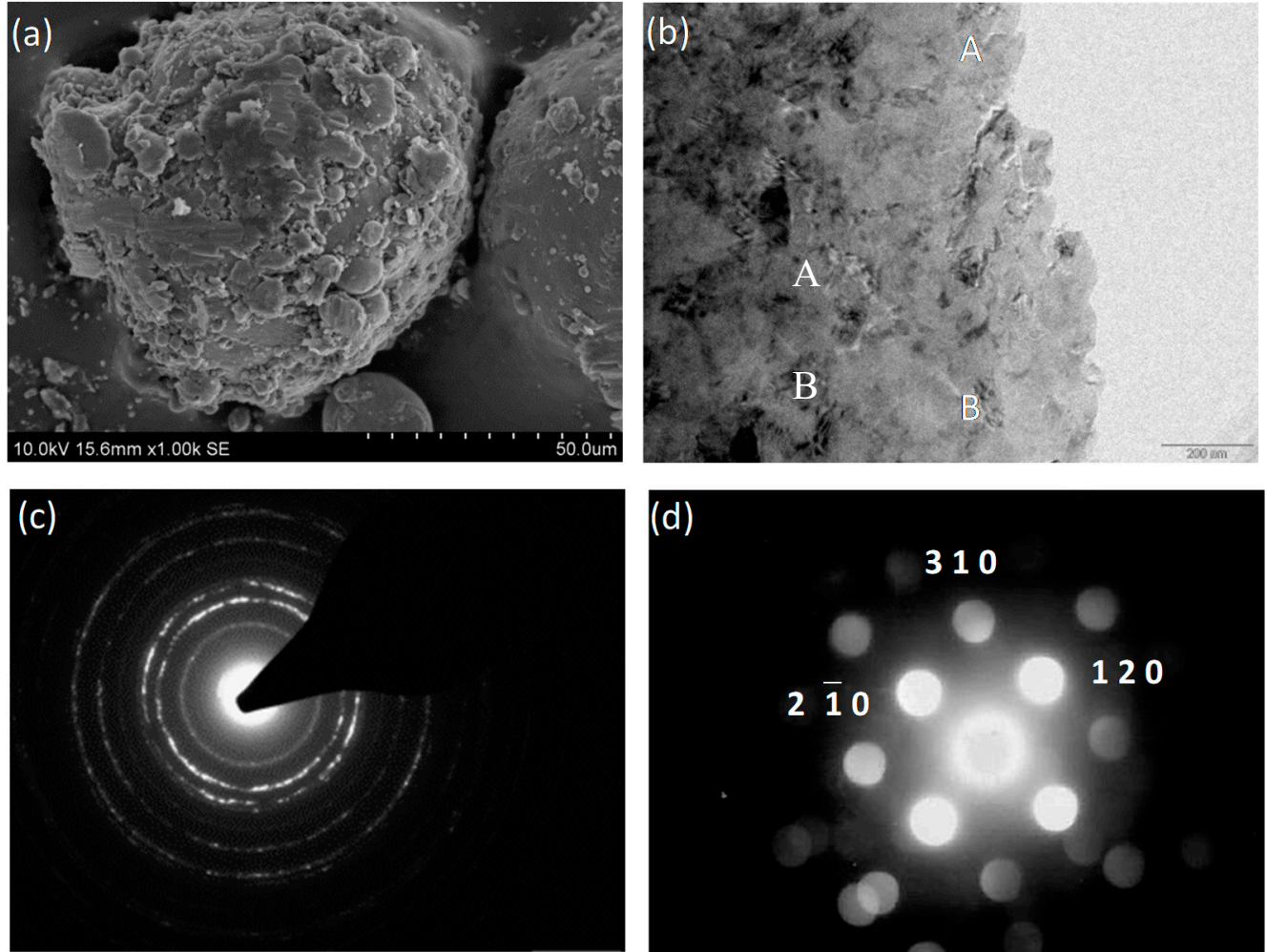

Figure 4. (a) Al-12Si/AlN powder SEM micrograph; (b) TEM bright field (BF) micrograph of Al-12Si/AlN particle surface; (c) ED of Al-12Si/AlN, Zone A; (d) ED of Al-12Si/AlN, Zone B.
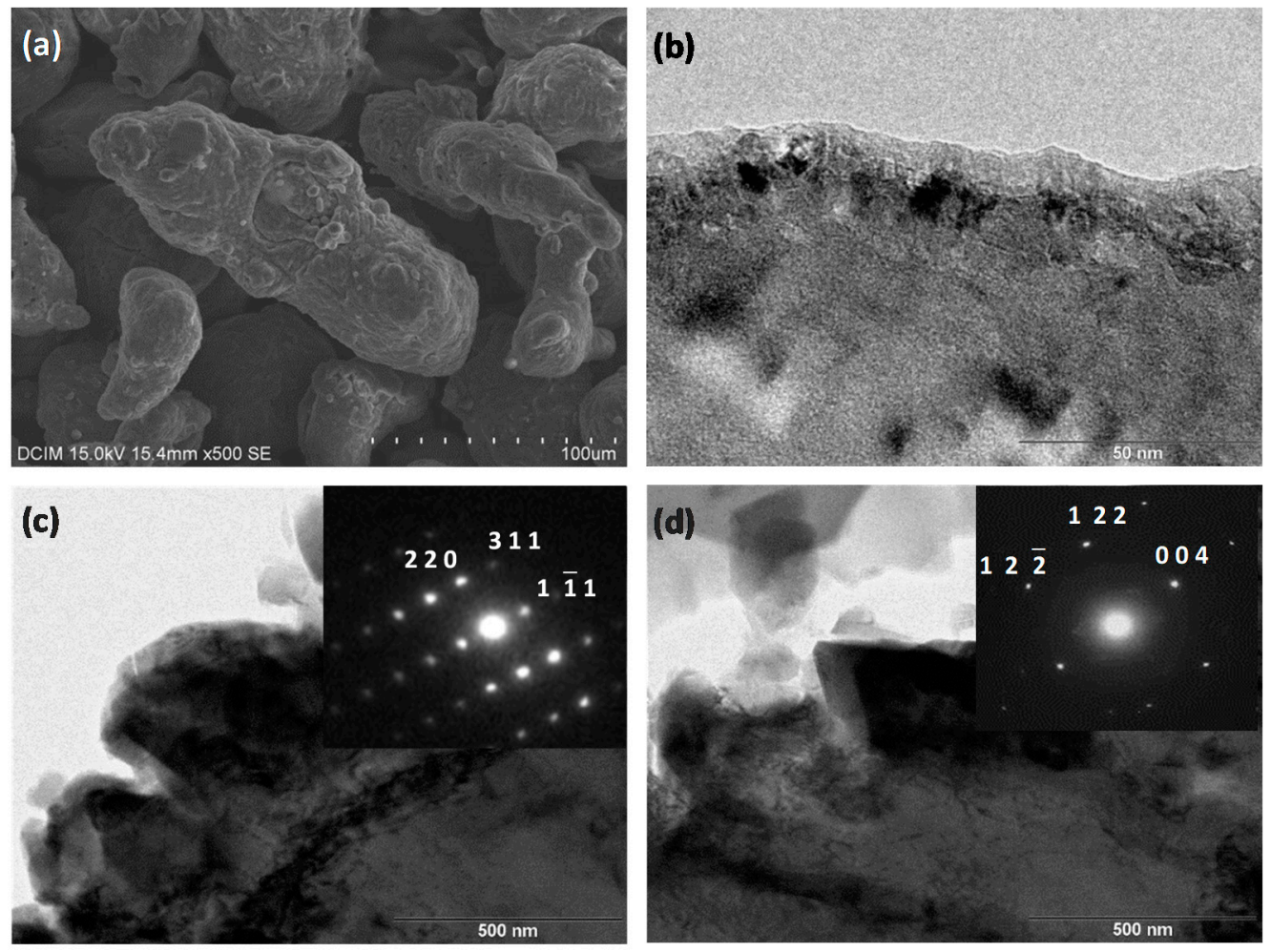

Figure 5. (a) AA6061 after the laser treatment; (b) Detail of the AA6061/AIN interface. TEM image; (c) ED of AA6061/AlN, cubic structure; (d) ED of AA6061/AlN, hexagonal structure. 


\subsection{Microstructure of Al/AlN DLD Layer}

Figure 6 shows the microstructures of the different coatings made of $\mathrm{Al}$ alloys reinforced with AlN particles fabricated using the DLD parameters shown in Table 3 and their corresponding EDX analysis. Figure 6a shows that in the pure aluminium matrix composite, the AlN reinforcement in situ was formed in the matrix. The measured reinforcement percentage was $10 \mathrm{vol} \%$. Most of the AlN particles, particularly those of smaller size, were distributed in the matrix, although in some zones, AlN particles agglomerated forming rings, which was possibly because of the mass transfer fluxes caused by the Marangoni effect. The AlN particles size was below $2 \mu \mathrm{m}$ (Figure 6b).
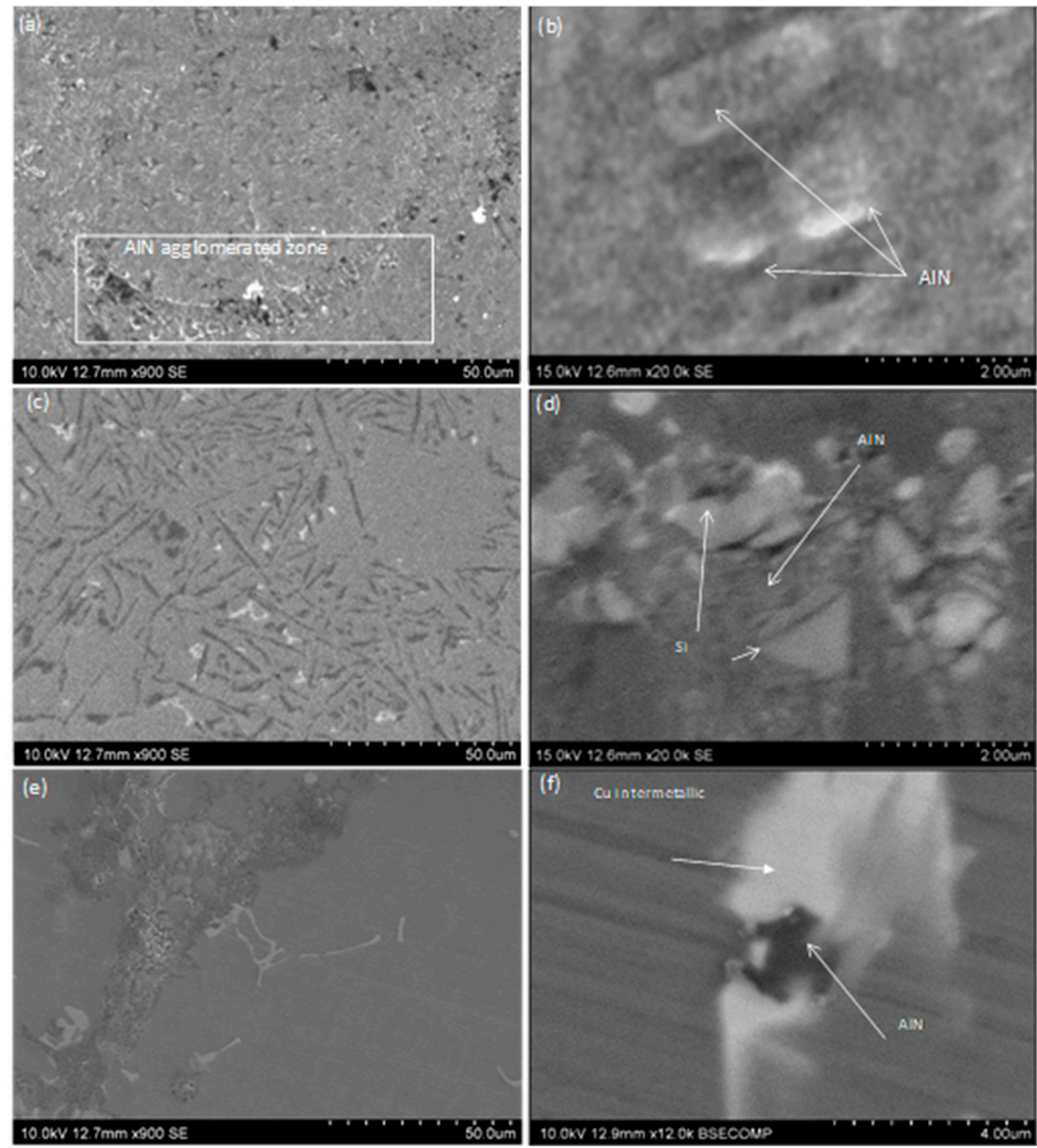

Figure 6. (a) Cross-section of Al/AIN coating on AA6082 aluminium alloy; (b) detail of the AlN particles on Al/AlN coating; (c) Al-12Si/AlN coating microstructure; (d) detail of the AlN particles on Al-12Si/AlN coating; (e) AA6061/AlN; (f) detail of the AlN particles on AA6061/AlN coating.

The Al-12Si/AlN microstructure shown in Figure $6 \mathrm{c}$ consists of an aluminium-eutectic silicon matrix reinforced with AlN particles. The AlN size was below $1 \mu \mathrm{m}$ (Figure 6d), and the distribution of particles was more homogeneous than in the case of using a pure $\mathrm{Al}$ matrix. Figure 6e shows the microstructure of the AA6061/AlN composite; in this case, apart from AlN particles, Cu intermetallic 
was also observed. The AlN aggregates' average size was $1 \mu \mathrm{m}$, as observed by SEM, and many particles were observed near the $\mathrm{Cu}$-intermetallic precipitates (Figure 6f).

\subsection{Microhardness Measurements}

In order to evaluate the effect of the AlN reinforcement in the properties of the layers deposited, both reinforced and unreinforced $\mathrm{Al}$ were fabricated by DLD, using in all cases the parameters shown in Table 3 and using nitrogen and argon, respectively.

Figure 7a shows the average Vickers microhardness of the different coatings and of the substrate. In all cases, the microhardness was lower in the unreinforced coatings. As a reference, the hardness of the substrate was $90 \pm 5 \mathrm{HV}_{0.1}$; this value is common in this alloy, and it is due to the alloying elements of the AA6082 and to the formation of $\mathrm{Cu}$ precipitates in the AA6082. The hardness of the unreinforced Al layer was $80 \pm 5 \mathrm{HV}_{0.1}$, which is lower than that of the substrate. The incorporation of in situ formed AlN particles increased the hardness by $65 \%$ to $123 \pm 10 \mathrm{HV}_{0.1}$. In the case of the Al-12Si alloy, the unreinforced coating microhardness was $95 \pm 5 \mathrm{HV}_{0.1}$, which is similar to the substrate hardness. In this case, the incorporation of the AlN reinforcement increased the hardness by more than $35 \%$ to $150 \pm 10 \mathrm{HV}_{0.1}$, which is a very high hardness value for $\mathrm{Al}$ composites. Finally, the unreinforced AA6061 layers had a hardness of $60 \pm 10 \mathrm{HV}_{0.1}$, which increased by $20 \%$ to $75 \pm 10 \mathrm{HV}_{0.1}$ by forming the AlN particles in the alloy.

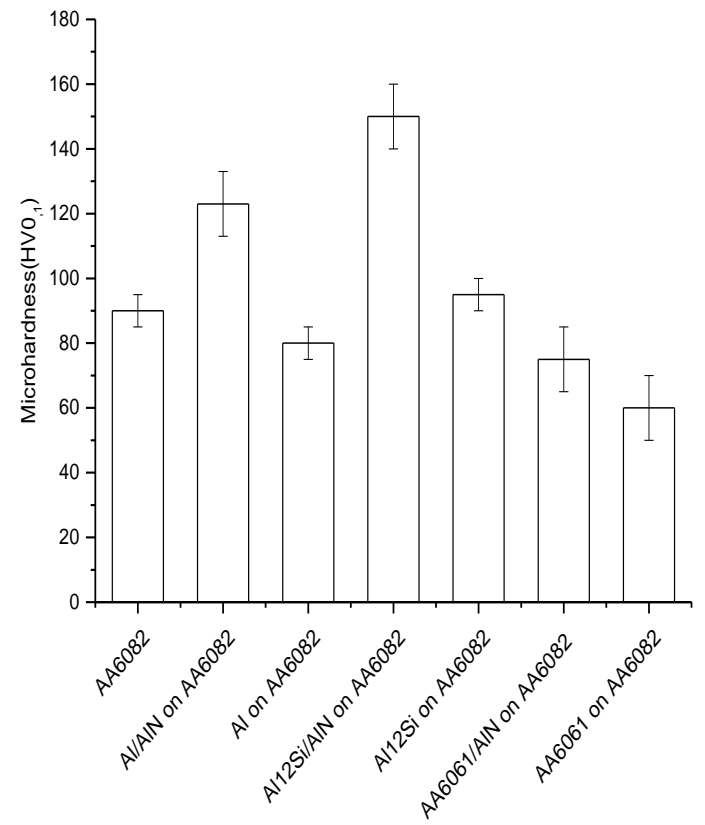

(a)

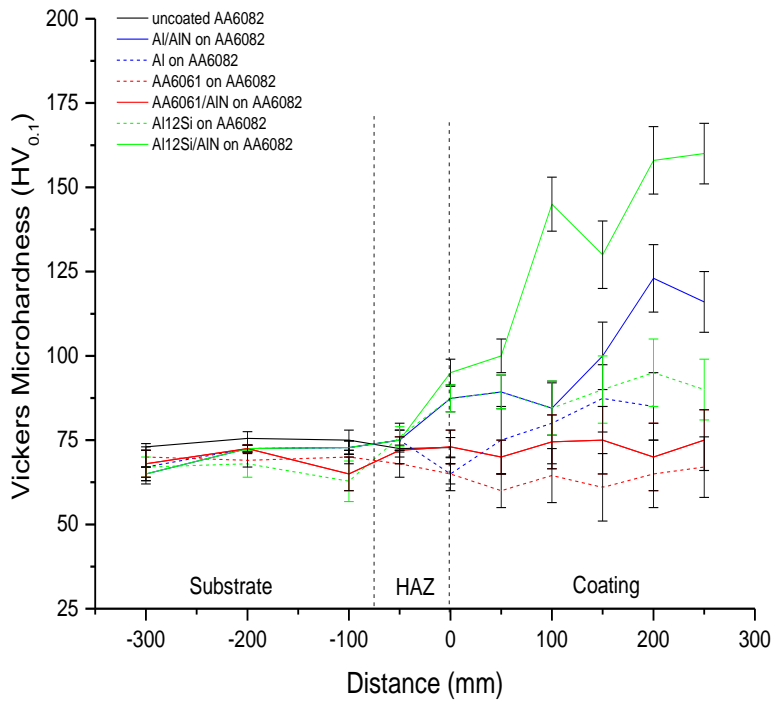

(b)

Figure 7. (a) Coatings and substrate average Vickers microhardness $\left(\mathrm{HV}_{0.1}\right)$; (b) Vickers microhardness $\left(\mathrm{HV}_{0.1}\right)$ evolution along the coatings and the substrate.

The microhardness evolution across the coatings and the substrate is shown in Figure $7 \mathrm{~b}$. The microhardness across the Al, Al-12Si, and AA6061 coatings fabricated without reinforcement (blue, green, and red dashed lines) were similar to the substrate microhardness. However, the Al/AlN and $\mathrm{Al}-12 \mathrm{Si} / \mathrm{AlN}$ coatings (blue and green lines) showed that the hardness increased from the substrate interface to the top of the coating. This evolution of the microhardness is common in laser cladding because the top of the coating cools off at a faster rate than the bottom [4]. This effect was not accentuated in the AA6061/AlN coating (red line), which had a microhardness that was similar to that of the substrate. 
In all cases, the hardness increase caused by the presence of nano-sized AlN particles is explained because they can act as grain nucleants and thus establish a control in the solidification during the DLD process. The addition of nucleants in aluminium alloy powders used for additive manufacturing resulted in crack-free materials, with equiaxed fine-grained microstructures [19].

In the HAZ, we observed a change in the hardness without the presence of nitrides. This suggests that the increase in hardness is caused by the DLD process. In this zone, different phenomena take place: the outer zone of the substrate is heated, but the temperature increase is smaller than the temperature of the coating deposited, so that the thermal contraction of the coating is greater than that of the substrate. This induced compressive forces in this zone of the substrate. On the other hand, the microstructure in this zone is similar to a casting microstructure. On the HAZ, the microstructure showed columnar grain growth in the solidification direction perpendicular to the isotherm. In addition, the molten pool zone is small and is formed by equiaxial grains smaller than the uncoated substrate $[4,20]$.

The correlation between the coating microstructure with the nanohardness and Young's modulus has been analysed by nanoindentation mapping studies. Figure $8 \mathrm{a}-\mathrm{c}$ shows the different coatings microstructure (a column) and its nanohardness (b column) and Young's modulus map (c column) for the three reinforced systems. A direct relationship between the microstructure and the mechanical properties has been determined. In all cases, the AlN particles' hardness was $30 \pm 5 \mathrm{GPa}$ (the values are similar to those measured in previous studies for $\mathrm{Al} / \mathrm{SiCp}$ composites coatings [20]).

(a)

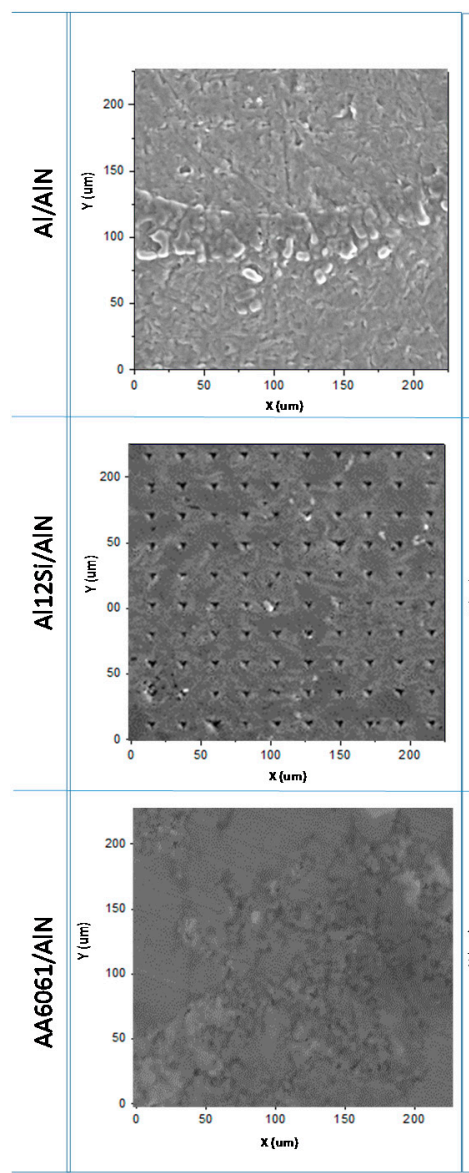

(b)
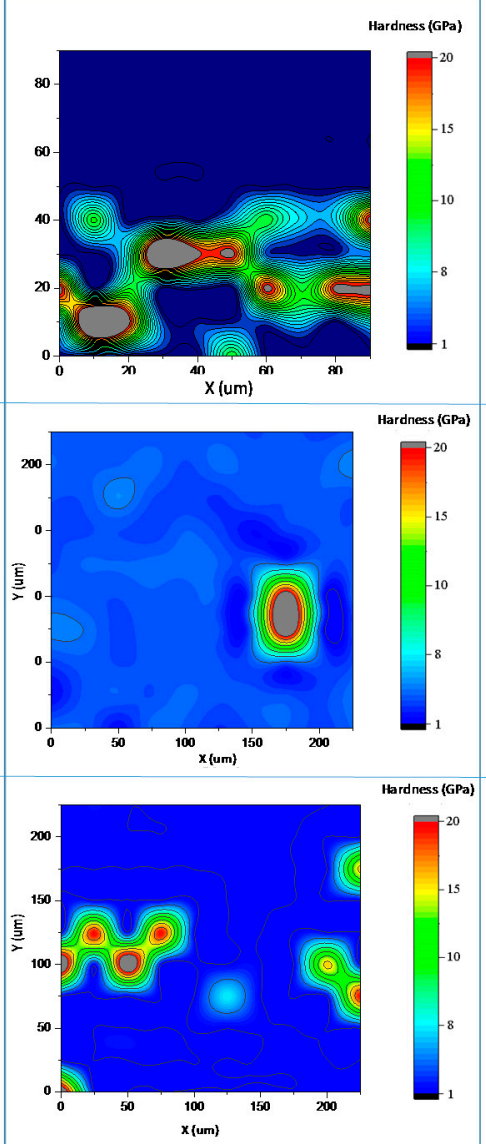

(c)
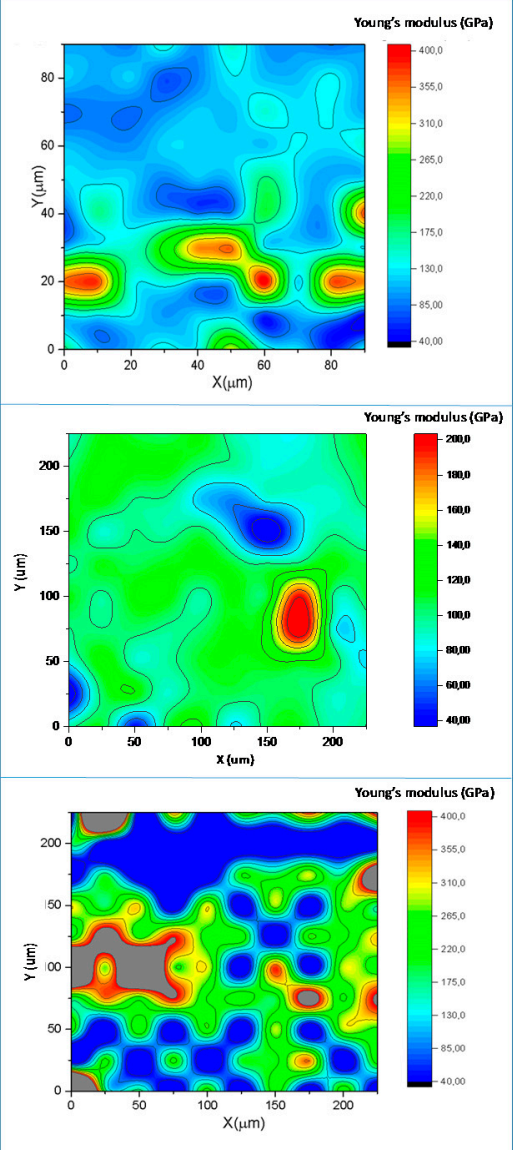

Figure 8. (a) $\mathrm{Al} / \mathrm{AlN}, \mathrm{Al}-12 \mathrm{Si} / \mathrm{AlN}$, and AA6061/AlN microstructure; (b) $\mathrm{Al} / \mathrm{AlN}, \mathrm{Al}-12 \mathrm{Si} / \mathrm{AlN}$, and AA6061/AlN hardness map on the zone shown in a); (c) Al/AlN, Al-12Si/AlN, and AA6061/AlN Young's modulus map on the zone shown in a). 


\section{Discussion}

In the DLD process, metallic particles carried in a gas are heated with a laser so that these particles are molten and deposited in a surface where they solidify and form a new structure. In this work, we have used nitrogen as the carrying gas in order to cause a reaction between the nitrogen atmosphere and the molten aluminium of the alloys used. As a result of the interaction, AlN particles are formed, and they are incorporated in the deposited material, giving place to a composite deposited material.

This process has been carried out with particles that have different shapes, sizes, and compositions. All these characteristics may have an effect in the interaction between the powder particles and the laser beam, and between the molten aluminium particles and the surrounding nitrogen atmosphere.

The amount of AlN formed depends on the speed of the nitriding reaction, which in turn depends on the temperature and the composition of the alloys used. To determine the temperature of the powder in the laser beam, the powder temperature distribution for the conditions used has been modelled using the equations provided by Pinkerton [21]:

$$
T(Z, R)=T_{0}+\frac{3 \alpha}{4 \rho c r_{p}}\left[\frac{P_{A}}{v_{P Z}^{\prime}} \int_{z \prime(L)}^{Z} I\left(z, r^{\prime}(z)\right) d z+\frac{P_{B}}{v_{P Z}^{\prime \prime}} \int_{z^{\prime \prime}(L)}^{Z} I\left(z, r^{\prime \prime}(z)\right) d z\right]
$$

where $T(Z, R)$ is the temperature distribution of the powder along the spraying path $\left(0<z \leq \mathrm{s}_{\mathrm{n}}\right), T_{0}$ is the initial powder temperature, $\alpha$ is the absorptivity, $\rho$ is the particle density, $c$ is the specific heat capacity, $r_{p}$ is the particle radius, $P_{A}$ and $P_{B}$ are the powder proportion following path $A$ (the largest one) and path $\mathrm{B}$ (the shortest one), $v_{p z}^{\prime}$ and $v_{p z}^{\prime \prime}$ are the powder velocities in path A or B in the $\mathrm{z}$ (axial) direction, and $r$ and $z$ are the radial and axial positions.

The model was implemented using Matlab 7.0 software and the diagram of the coaxial laser deposition nozzle used, and the powder and gas flux are shown in Figure 8a. The temperature distribution of the sprayed particles during the fabrication process at the focal plane is plotted in Figure $9 \mathrm{~b}$ for the different powders used.

(a)

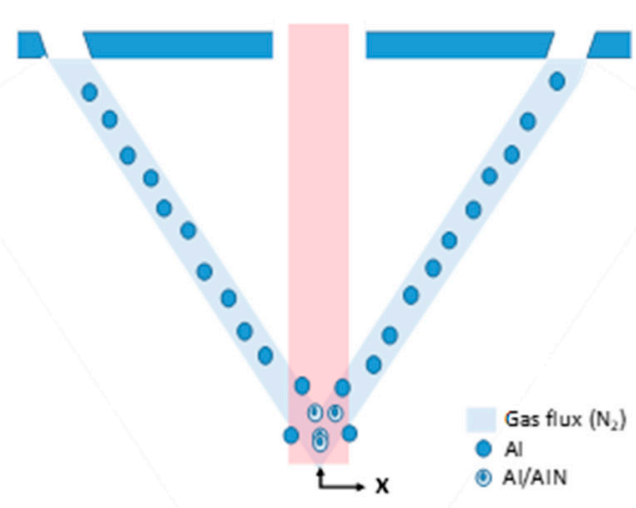

(b)

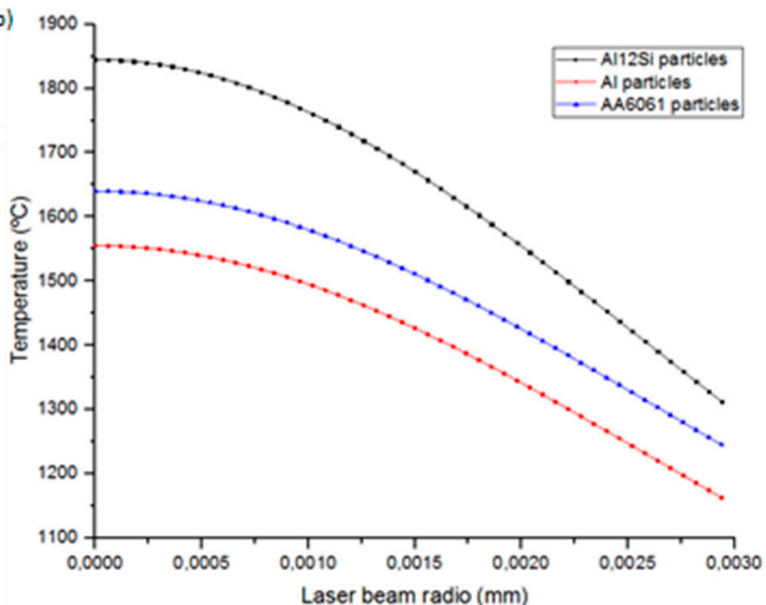

Figure 9. Temperature distribution for (a) diagram of the coaxial laser deposition nozzle used and the powder and gas flux (b) temperature distributions of the sprayed particles.

The temperatures obtained for Al pure particles with the model (Figure 9b, blue line) are between 1160 and $1640{ }^{\circ} \mathrm{C}$; for Al-12Si particles (Figure 9b, black line), they are between 1312 and $1845^{\circ} \mathrm{C}$; and for AA6061 particles (Figure 9b, red line), they are between 1244 and $1555{ }^{\circ} \mathrm{C}$. These different temperature ranges are mainly caused by the difference in particle size (Table 1). As it happens in all systems, the smaller the particles, the larger the area-to-volume ratio they have. In addition, as the radiation absorption in associated with the area of the particle exposed to the laser radiation, 
there is a higher radiation absorption of energy per unit mass in smaller particles. Therefore, smaller particles reach higher temperatures.

On the one hand, the temperature reached by the particles exceeds their melting point by a large margin, indicating that they are in liquid state for most of the travel time, and it allows them to react with the surrounding nitrogen with a high reaction kinetics, giving place to the formation of nitrides. In addition, the surface-to-volume ratio that micro-sized particles have is very high, so the area in which the reaction can take place is also very high. On the other hand, the reaction time is very short, reducing the total amount of nitrides that can be formed and reducing the size of the nitrides formed.

Daniel et al. [22] found that all these factors cause the reaction mechanism type to be conducted by its surface, which is also expected in environments with low nitrogen pressure. All these aspects are different from the processes that take place by insufflating nitrogen in molten aluminium pools, such as in direct melt nitridation (the PRIMEX method) in which the aluminium temperature is much lower and the ratio of the surface of the molten aluminium exposed to nitrogen is much smaller, but the interaction time can be extended for long periods of time.

For the three types of alloy powders used, the results indicate that the nitridation reaction has taken place, showing that the temperature and the reaction time have been high enough in all cases (Figure 9b). Therefore, the differences observed in the crystalline structures formed must be explained by considering other factors such as the non-equilibrium conditions in which the reaction takes place, the particle size, and the elementary composition of the alloys used (Mg and $\mathrm{Si}$ ).

Schemerler and Kortus [23] found that the AlN crystalline phase formed depends on temperature and pressure; they suggest that under equilibrium conditions at room temperature, AlN is stable in its hexagonal form. AlN shows cubic structure at high temperatures, and its structure changes to the hexagonal form at lower temperatures. The phase transition mechanism from cubic to hexagonal depends on free energy and temperature, and the transition path in the absence of pressure leads to the achievement of a stable hexagonal phase. However, in a particle immersed in a solid, the residual stress may limit this transformation. Both structures show high mechanical properties, although the mechanical strength and thermal conductivity are higher in cubic AlN than in its hexagonal structure.

The laser fabrication process is a very rapid process that takes place on the surface of the Al particles, forming AlN nanoparticles. In addition, the temperature distribution across the laser beam follows a Gaussian distribution with its maximum placed at the centre of the laser beam (Figure 9) so the deposited particles may have had a different thermal story.

Kudyakova et al. [24] obtained similar results in other AlN synthesis methods and as they explained, most of the research concerning the in situ fabrication of AlN particles has focused on the wurtzite crystal phase. Yuechun et al. [25] established that the formation of a cubic structure is possible in non-equilibrium conditions using an excimer laser fabrication process. Other authors $[24,26]$ found that the cubic phase nucleation occurs when the reaction takes place under high-energy conditions such as in the case of plasma spraying. In our case, the use of an HPLD results in a similar situation.

Nitridation in non-equilibrium conditions and the effect of the particle size are very important factors in the AlN crystalline structure obtained. In the Al-12Si, only the cubic AlN phase was observed (Figure 4). This can be explained because these particles reach the highest temperature of the three studied, getting values above across all laser beams. Therefore, all the AlN is formed in the cubic phase. Afterwards, the cooling of the particles is very fast, as it takes place when the molten particle comes into contact with the surface. The great temperature difference between the particle and the surface and the small mass of the particles (they are the smallest of all tested particles) causes the cubic AlN phase to quench in the layer formed.

In the case of $\mathrm{Al}$ and AA6061 particles, both crystalline structures (cubic and hexagonal) have been observed (Figures 3 and 5, respectively) in contrast to Al-12Si ones. This can be explained by considering that the $\mathrm{Al}$ particles are slightly larger than the Al-12Si ones, so that they reach lower temperatures during the manufacture of $\mathrm{Al} / \mathrm{AlN}$ powder (Figure 9b). Norrby et al. [27] reported that in a first stage, cubic AlN grows on the aluminium surface, and in a second stage, cubic AlN undergoes 
a polymorphic transition into the hexagonal phase. The polymorphic transition is allowed due to the slower solidification speed because of the lower particle temperature compared to the Al-12Si ones. On the other hand, the AA6061 powder has a very heterogeneous size distribution (Figure 1c), so that large particles will have a similar behaviour to Al powder and smaller particles will behave similar to the Al-12Si powder.

Figure 10 shows schematically the process described above, and the temperature evolution of the particles is represented. Al-12Si particles have a higher cooling speed than pure Al and AA6061 particles, and this lower cooling speed allows the polymorphic transition from cubic to hexagonal AlN.

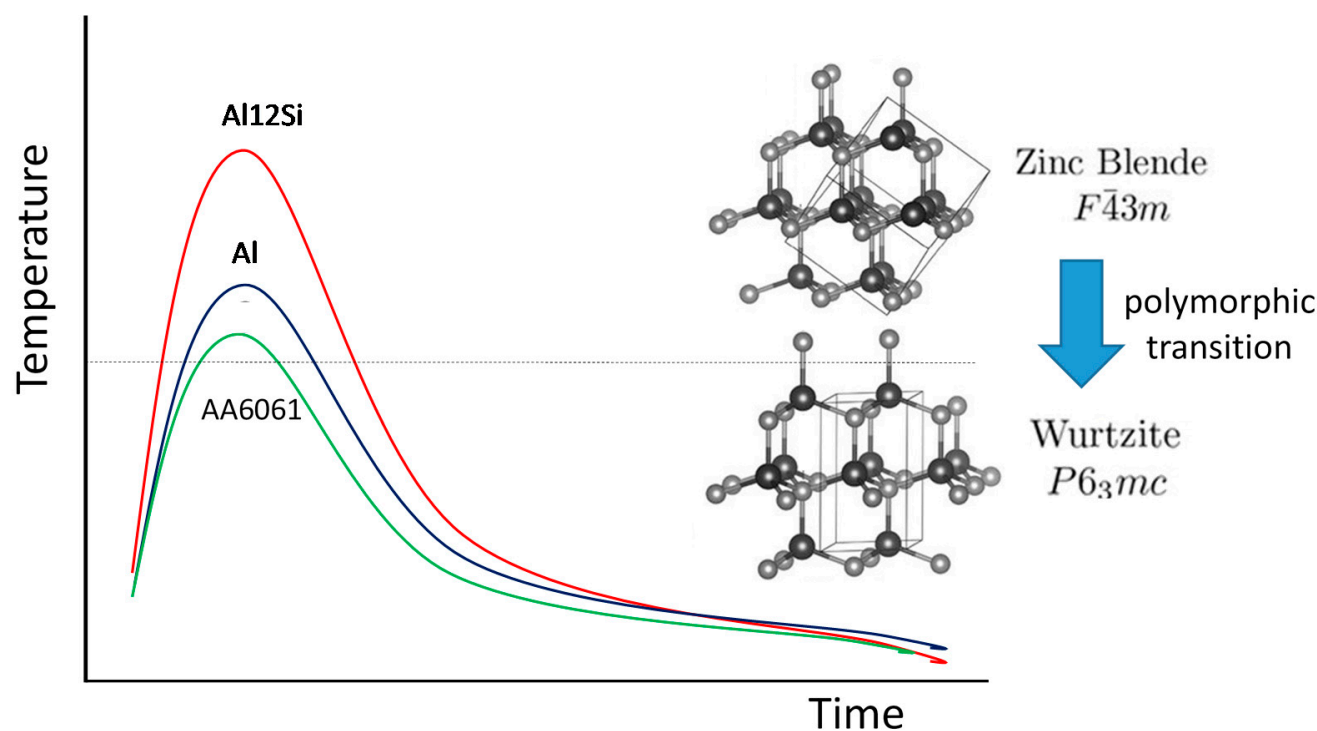

Figure 10. Particle temperature achieved against time for the different aluminium alloys used and representative temperature of the polymorphic transition or AlN, showing the time in which the aluminium alloy is at a temperature at which AlN is in its cubic structure (Zinc Blende).

Furthermore, the effect that the alloying elements have on the nitridation reaction must also be considered. In the case of $\mathrm{Al}$, there is a reaction between the metal powder and nitrogen according to the reaction shown in Equation (1), as there are no other elements in the alloy. In this case, the powder temperature is high enough to promote the nitridation reaction, and the AlN formed has both cubic and hexagonal structures (Figure 3).

In the Al-12Si particles, the presence of Si does not catalyse the formation of AlN, so there is a direct reaction between $\mathrm{Al}$ and $\mathrm{N}$ following the mechanism shown in Equation (1). In this case, only the cubic AlN phase was formed (Figure 4). Apart from the higher temperature of the powder, this can be due to the presence of silicon, which reduces the AlN reaction speed, as it has been described in this kind of system [22]. Figure 11a shows schematically the reaction mechanism described above for Al and Al-12Si particle nitridation. The higher temperatures achieved dissociates the diatomic nitrogen, which reacts with molten aluminium particles, forming AlN nanoparticles on the aluminium surface by direct nitridation.

Finally, in the case of AA6061 particles, both cubic and hexagonal AlN structures were observed (Figure 5). This is due to the opposite effect of magnesium and silicon, which are both alloying elements. Magnesium acts as a reaction catalyst; it changes the reaction mechanism from the one indicated by Equation (1) to a mechanism in which there is a reaction between $\mathrm{Mg}$ and $\mathrm{N}_{2}$ according to Equations (4) and (5), forming $\mathrm{Mg}_{3} \mathrm{~N}_{2}$. Subsequently, aluminium reacts with $\mathrm{Mg}_{3} \mathrm{~N}_{2}$ and forms $\mathrm{AlN}$ according to Equation (6):

$$
\mathrm{Al}(\mathrm{Mg}) \rightarrow \mathrm{Al}(\mathrm{l})+\mathrm{Mg}(\mathrm{g})
$$




$$
\begin{gathered}
3 \mathrm{Mg}+2[\mathrm{~N}] \rightarrow \mathrm{Mg}_{3} \mathrm{~N}_{2} \\
2 \mathrm{Al}+\mathrm{Mg}_{3} \mathrm{~N}_{2} \rightarrow 2 \mathrm{AlN}+3 \mathrm{Mg} .
\end{gathered}
$$

The global reaction is:

$$
\mathrm{Al}+[\mathrm{N}] \rightarrow \mathrm{AlN}
$$

This mechanism is more favourable than the direct reaction between $\mathrm{Al}$ and $\mathrm{N}_{2}$ [28]. In this case, a larger amount of AlN with hexagonal structure should be expected. However, the inhibiting effect of Si reduces the kinetics of the reaction, so that both crystalline structures are present at the surface of the particles.

Figure $11 \mathrm{~b}$ shows the mechanism described above for AA6061 particles. First, there is a reaction between $\mathrm{Mg}$ and $\mathrm{N}_{2}$ to form $\mathrm{Mg}_{3} \mathrm{~N}_{2}$, which is quickly followed by a reaction between $\mathrm{Mg}_{3} \mathrm{~N}_{2}$ and aluminium to form AlN. Then, the formation of AlN nanoparticles is conducted by the combination of the following reaction mechanisms: direct nitridation for $\mathrm{Al}$ and Al-12Si particles, catalysed nitridation by the presence of $\mathrm{Mg}$ in AA6061, and by the evolution of temperature of the particles, with higher temperatures and faster cooling in the Al-12Si powder. This results in the formation of mixtures of hexagonal and cubic AlN in pure $\mathrm{Al}$ and in AA6061, and only cubic AlN in the Al-12Si particles.

(a)

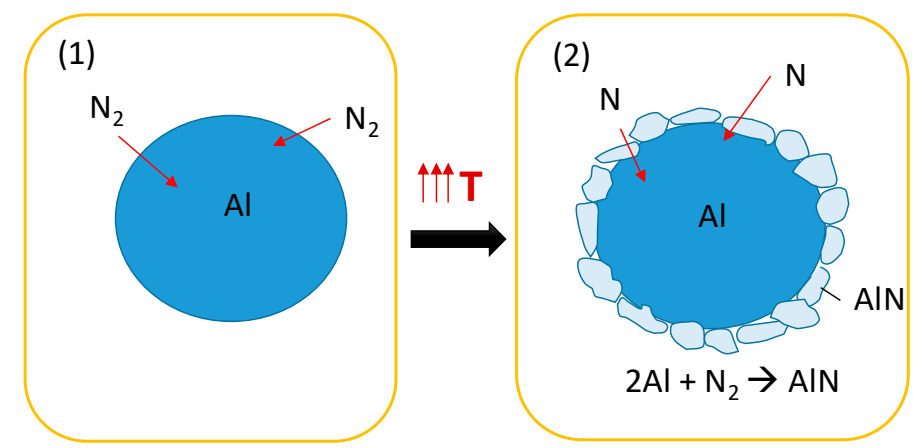

(b)
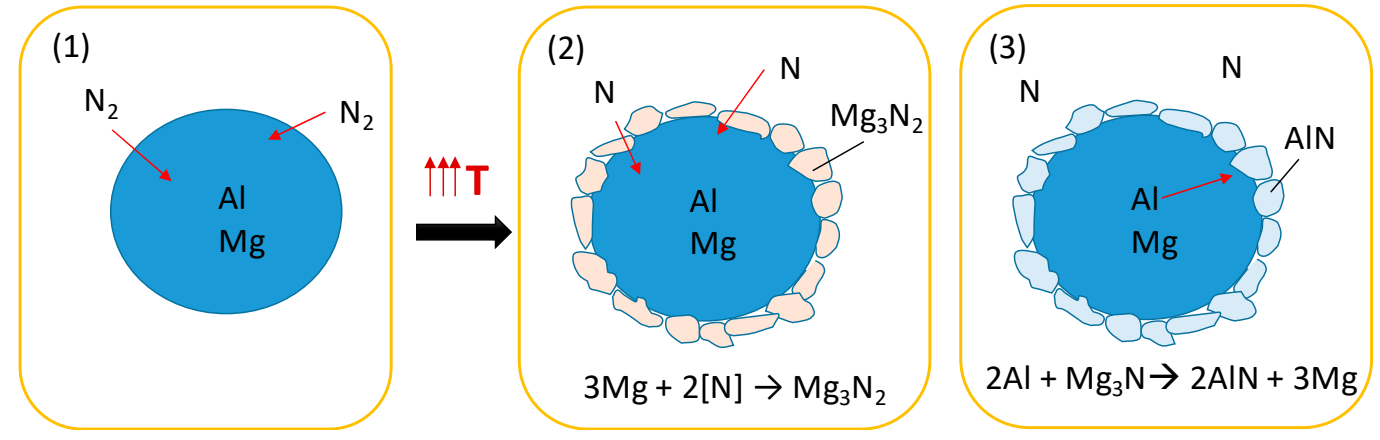

Figure 11. Nitridation mechanism; (a) for $\mathrm{Al}$ and Al-12Si particles; (b) for AA6061 particles.

The characterisation of the laser-treated powder showed that the shape of the particles did not suffer considerable superficial changes (Figures 3-5), making them valid for the same manufacturing processes as the initial powder, i.e., powder metallurgy and thermal spraying. Therefore, they are suitable to the DLD process. The images of the layers (show) that there was continuity in the layer, and no significant defects appeared with any of the materials tested.

The hardness of the alloys deposited without reinforcement for the pure Al, Al-12Si, and AA6061 layers was 80,95 , and $60 \mathrm{HV}_{0.1}$, respectively. These values are similar to those of the substrate used and are common values for these alloys [4]. The incorporation of AlN increased the hardness of the alloys, and the hardness was 123, 150, and $75 \mathrm{MPa}$ for the Al/AlN, Al-12Si/AlN, and AA6061/AlN, respectively.

For the different systems, the hardening effect can be associated with the Orowan effect in which hard particles limit the movement of dislocations in the matrix, causing an increase in the hardness 
of the material. In our case, the AlN particles would play a role equivalent to that of strengthening precipitates in aluminium alloys. Another hardening effect that can take place is the Hall-Petch effect in which the grain boundaries act as pinning points limiting dislocation propagation, so that a reduction in the grain size causes a hardness increase. In our systems, the fast cooling of the aluminium alloy is further favoured by the presence of nanosized particles that favour solidification and could modify the grain size of the alloy.

The increase of the microhardness of the in situ reinforced $\mathrm{Al}$ alloys have been shown in Figure 7. The differences between samples can be attributed to the different nitridation mechanisms that take place. Coatings obtained with a direct nitridation mechanism (Figure 11a) had a higher microhardness than the coating obtained with the two-step mechanism (Figure 11b). For this reason, Al/AlN and Al-12Si/AlN had a higher microhardness than AA6061/AlN, which is formed by two-step nitridation.

In addition, the inhibiting effect of $\mathrm{Si}$ that affects the kind of AlN atomic structure formed also seems to have an impact on the microhardness of the samples. In this respect, samples reinforced with cubic AlN (Al-12Si/AlN) presented higher microhardness than samples reinforced with a mix of hexagonal and cubic AlN (Al/AlN and AA6061/AlN).

The hardness values of the AA6061 layers were lower than the other ones. In this case, the lower values can be associated with the absence of any heat treatment to the alloy; as observed in composites made by powder metallurgical processing [29], the hardness of both would be strongly increased by using an optimised heat treatment. In any case, the presence of AlN particles increased the hardness by more than $20 \%$.

The presence of AlN locally increased the hardness and the Young's modulus value (Figure 8). When the reinforced particles were deposited at the surface, the AlN particles are distributed throughout the layer, as it has been shown in Figure 6, and they were completely integrated in the aluminium matrix. This effect is very relevant as one of the main problems observed in the fabrication of aluminium matrix composites reinforced with ceramic particles is the presence of pores and defects due to the limited wettability of ceramics by the molten aluminium [3]. In this case, as the particles grow from the molten aluminium, they are wet before the deposition on the surface, and their integration in the matrix is favoured. Moreover, as the solidification takes place very fast, the solidification front does not push the particles, and they stay well distributed in the layer.

\section{Conclusions}

i. An innovative fabrication process to obtain $\mathrm{Al} / \mathrm{AlN}$ composite powder was developed using Direct Laser Deposition. Aluminium powder and $\mathrm{N}_{2}$ are sprayed along the laser beam so that the laser heats the particles and induces the nitridation reaction of the aluminium particles. The presence of an in situ AlN reinforcement has been confirmed by different analysis techniques. The laser treatment does not change the powder size and shape; it only slightly increases its roughness. So, the powder treated can be used in the same manufacturing processes as that of the initial powder.

ii. The effect of using different aluminium alloys has been evaluated. There is a correlation between particle size, composition, and temperature of the sprayed particles in the laser beam and the crystalline structure of AlN formed.

iii. The sprayed particles' temperature distribution depends on the particle size so that smaller particles reach higher temperatures. Al/AlN particles heat up to temperatures between 1565 and $1640{ }^{\circ} \mathrm{C}$, and the AlN structure is both cubic and hexagonal. Al-12Si/AlN particles achieve temperatures between 1760 and $1845^{\circ} \mathrm{C}$, and the AlN structure is cubic. AA6061/AlN particles achieve temperatures between 1485 and $1555^{\circ} \mathrm{C}$, and the AlN structure is both cubic and hexagonal. The presence of hexagonal AIN is favoured against cubic in larger particles where the temperature reached is lower. 
iv. Two different reaction mechanisms are proposed. The first is the direct reaction between aluminium and nitrogen. This occurs when the initial powder is either Al or Al-12Si. The second mechanism combined the first reaction mechanism with a secondary reaction between $\mathrm{Mg}$ and $\mathrm{N}_{2}$, followed by a reaction between $\mathrm{Mg}_{3} \mathrm{~N}_{2}$ and aluminium to form AlN. This occurs when the initial powder is AA6061. Magnesium acts as a reaction catalyst and silicon acts as an inhibiting alloying element.

v. The coatings that had AlN particles showed increases in hardness of up to 65\% compared to the unreinforced material. The hardening effect can be associated with the Orowan and Hall-Petch effects. Al/AlN and Al-12Si/AlN coatings were obtained by direct nitridation and had higher microhardness than AA6061/AlN coatings that have been obtained with the two-step mechanism.

vi. The AlN particles were completely integrated in the aluminium matrix, which is explained because they are formed from the molten aluminium. The solidification takes place very fast, so the solidification front does not push the particles, and they stay well distributed in the layer, reducing the presence of pores and defects, increasing the microhardness, and providing a homogenous stiffness value.

Patents: P. Rodrigo: A. Riquelme; M.D. Escalera-Rodriguez; J. Rams. Procedimiento de obtención de material compuesto $\mathrm{Al} / \mathrm{AlN}$ o Ti/TiN, material compuesto $\mathrm{Al} / \mathrm{AlN}$ o Ti/TiN obtenible según dicho procedimiento y uso del mismo en revestimientos.07/09/2017. ES2598727.

Author Contributions: Investigation, A.R.; writing-original draft, A.R.; writing-review \& editing, P.R., M.D.E.-R., P.G.-F. and J.R. All authors have read and agreed to the published version of the manuscript.

Funding: This research was funded by: Comunidad de Madrid (ADITIMAT-CM S2018/NMT-4411) and ADITINANO 2020/00007/019), Universidad Rey Juan Carlos (2020/00006/004) and Agencia Estatal de Investigación (RTI2018-096391-B-C31).

Conflicts of Interest: The authors declare no conflict of interest.

\section{References}

1. Mrówka-Nowotnik, G.; Sieniawski, J.; Wierzbiñska, M. Intermetallic phase particles in 6082 aluminium alloy. Arch. Mater. Sci. Eng. 2007, 28, 69-76.

2. Birol, Y. The effect of processing and Mn content on the T5 and T6 properties of AA6082 profiles. J. Mater. Process. Technol. 2006, 173, 84-91. [CrossRef]

3. Lai, S.W.; Chung, D.D. Consumption of $\mathrm{SiC}$ whiskers by the Al-SiC reaction in aluminium-matrix $\mathrm{SiC}$ whisker composites. J. Mater. Chem. 1996, 6, 464-477. [CrossRef]

4. Ureña, A.; ESCALERA; Rodrigo, P.; Baldonedo, J.L.; Gil, L. Active coatings for SiC particles to reduce the degradation by liquid aluminium during processing of aluminium matrix composites: Study of interfacial reactions. J. Microsc. 2001. [CrossRef]

5. Kumar, S.; Reddy, S.K.; Joshi, S.V. Microstructure and performance of cold sprayed Al-SiC composite coatings with high fraction of particulates. Surf. Coat. Technol. 2016. [CrossRef]

6. Rodrigo, P.; Poza, P.; Utrilla, V.; Ureña, A. Effect of reinforcement geometry on precipitation kinetics of powder metallurgy AA2009/SiC composites. J. Alloys Compd. 2009. [CrossRef]

7. Riquelme, A.; Escalera-Rodríguez, M.D.; Rodrigo, P.; Otero, E.; Rams, J. Effect of alloy elements added on microstructure and hardening of $\mathrm{Al} / \mathrm{SiC}$ laser clad coatings. J. Alloys Compd. 2017, 727. [CrossRef]

8. Shalaby, E.A.M.; Churyumov, A.Y. Development and characterization of A359/AlN composites for automotive applications. J. Alloys Compd. 2017. [CrossRef]

9. Borgonovo, C.; Apelian, D. Manufacture of Aluminum Nanocomposites: A Critical Review. Mater. Sci. Forum 2011, 678, 1-22. [CrossRef]

10. Lee, K.B.; Sim, H.S.; Kwon, H. Fabrication of Al/AlN composites by in situ reaction. J. Mater. Sci. 2006, 41, 6347-6352. [CrossRef]

11. Hou, Q.; Mutharasan, R.; Koczak, M. Feasibility of aluminum nitride formation in aluminum alloys_1995.pdf. Mater. Sci. Eng. A 1995, 195, 121-129. [CrossRef] 
12. Hall, B.J.; Schaffer, G.B.; Ning, Z.; McPhee, W.A.G.; Miller, D.N.; Drennan, J.; Gumming, D.J. Al/AlN layered composites by direct nitridation of aluminum. J. Mater. Sci. Lett. 2003, 22, 1627-1630. [CrossRef]

13. Borgonovo, C.; Apelian, D.; Makhlouf, M.M. Aluminum nanocomposites for elevated temperature applications. Jom 2011, 63, 57-64. [CrossRef]

14. Zhong, M.; Liu, W. Laser surface cladding: The state of the art and challenges. Proc. Inst. Mech. Eng. Part C J. Mech. Eng. Sci. 2010, 224, 1041-1060. [CrossRef]

15. Song, L.; Xiao, H.; Ye, J.; Li, S. Direct laser cladding of layer-band-free ultrafine Ti6Al4V alloy. Surf. Coat. Technol. 2016. [CrossRef]

16. Riquelme, A.; Rodrigo, P.; Escalera-Rodriguez, M.D.; Rams, J. Effect of the process parameters in the additive manufacturing of in situ Al/AlN samples. J. Manuf. Process. 2019. [CrossRef]

17. Xiong, Z.T.; Wu, G.T.; Hu, J.J.; Liu, Y.F.; Chen, P.; Luo, W.F.; Wang, J. Reversible hydrogen storage by a Li-Al-N-H complex. Adv. Funct. Mater. 2007, 17, 1137-1142. [CrossRef]

18. Dawes, J.R.; Bowerman, R.T. Introduction to the additive manufacturing powder metallurgy supply chain. Johnson Matthey Technol. 2015, 59, 243-256. [CrossRef]

19. Schuster, J.C.; Palm, M. Reassessment of the binary Aluminum-Titanium phase diagram. J. Phase Equilibria Diffus. 2006, 27, 255-277. [CrossRef]

20. Riquelme, A.; Rodrigo, P.; Escalera-Rodríguez, M.D.; Rams, J. Analysis and optimization of process parameters in Al-SiCp laser cladding. Opt. Lasers Eng. 2016, 78, 165-173. [CrossRef]

21. Pinkerton, A.J. An analytical model of beam attenuation and powder heating during coaxial laser direct metal deposition. J. Phys. D Appl. Phys. 2007, 40, 7323-7334. [CrossRef]

22. Daniel, B.S.S.; Murthy, V.S.R.; Murty, G.S. Metal-ceramic composites via in-situ methods. J. Mater. Process. Technol. 1997, 68, 132-155. [CrossRef]

23. Schmerler, S.; Kortus, J. Ab initio study of AlN: Anisotropic thermal expansion, phase diagram, and high-temperature rocksalt to wurtzite phase transition. Phys. Rev. B-Condens. Matter Mater. Phys. 2014. [CrossRef]

24. Kudyakova, V.S.; Shishkin, R.A.; Elagin, A.A.; Baranov, M.V.; Beketov, A.R. Aluminium nitride cubic modifications synthesis methods and its features. Review. J. Eur. Ceram. Soc. 2017, 37, 1143-1156. [CrossRef]

25. Yuechun, F.; Xianghai, M.; Weijia, Y.; Huan, H.; Xiaoming, S. Microstructure and optical properties of cubic AlN/TiN bilayers deposited by laser molecular beam epitaxy. Vacuum 2011, 85, 1037-1041. [CrossRef]

26. Shahien, M.; Yamada, M.; Yasui, T.; Fukumoto, M. Cubic aluminum nitride coating through atmospheric reactive plasma nitriding. J. Therm. Spray Technol. 2010, 19, 635-641. [CrossRef]

27. Norrby, N.; Rogström, L.; Johansson-Jesaar, M.P.; Schell, N.; Odén, M. In situ X-ray scattering study of the cubic to hexagonal transformation of AlN in Ti1xAlxN. Acta Mater. 2014, 73, 205-214. [CrossRef]

28. Changlin, Y.; Hebin, L.; Guiyun, C.; Feng, L. In Situ Synthesis and Formation Mechanism of AlN in Mg-Al Alloys. Rare Met. Mater. Eng. 2016, 45, 18-22. [CrossRef]

29. Ortiz, J.L.; Amigó, V.; Olvera, O.; Manzano, A.; Vorobiev, Y.V. A physical model for the aging of an aluminum-base alloy reinforced with nitride particles. Inorg. Mater. 2006. [CrossRef]

(C) 2020 by the authors. Licensee MDPI, Basel, Switzerland. This article is an open access article distributed under the terms and conditions of the Creative Commons Attribution (CC BY) license (http://creativecommons.org/licenses/by/4.0/). 